\title{
UMA VISÃO NÃO-LINEAR SOBRE ESTRATÉGIA EMPRESARIAL PELO PRISMA DA COMPLEXIDADE
} A NON-LINEAR VIEW OF BUSINESS STRATEGY THROUGH THE PRISM OF COMPLEXITY

\author{
Milton Luiz Wittmann \\ wittmann@profwittmann.com \\ Universidade Federal de Santa Maria - RS - Brasil.
}

\section{Rafael Mendes Lübeck}

rafael.lubeck@gmail.com

Pontíficia Universidade Católica do Rio Grande do Sul - PPGAd - RS - Brasil.

\section{Vinicius De Mesquita Nelsis}

vinicius.de.mesquita@gmail.com

Faculdade Senac Porto Alegre - RS - Brasil.

\section{Resumo}

0 presente artigo consiste em ensaio teórico entre as estratégias empresariais baseadas em pressupostos lineares, focados em planejamentos disciplinares e estratégias rigidamente estruturadas e a visão de estratégias baseadas em processos sistêmicos e complexos. A visão sistêmica da empresa e suas capacidades adaptativas, no entanto, ainda são insuficientes, pois a dinâmica do ambiente, no qual ocorre à estratégia, impõe a necessidade de realizar mudanças paradigmáticas ao longo do processo para moldar a estratégia definida a priori. Nas considerações finais infere-se a existência de uma contraposição entre os paradigmas cartesianos baseados em pressupostos lineares e mecanicistas de relações de causa e efeito com a teoria da complexidade e da autopoiese, propondo-se uma integração entre as visões que norteiam a elaboração das estratégias, argumento fortalecido pela VBM (Visão Baseada no Mercado) de Porter e a VBR (Visão Baseada em Recursos) de Penrose. Palavras-chave: Estratégia; Teoria da Complexidade; Visão Sistêmica

Abstract

The present article comprises a theoretical reflection business strategies based on linear assumptions, that emphasize planning and rigidly structured strategies, with those based on complex and systemic processes. The integrated vision of the company and its capabilities with the market, but still not enough, since the dynamics of the environment in which occurs the strategy imposes the need for adjustments throughout the process to shape the strategy defined a priori making this effective achievement of organizational objectives. The final considerations suggest the creation of an integrative theory combining the distinct visions that guide the development of strategies, an argument strengthened by Porter's MBV (Market Based View) and Penrose's RBV (Resource Based View).

Keywords: Strategy; Complexity Theory; Competitiveness; Resource-Based-View; Vision-Based on Market. 


\section{UMA VISÃO NÃO-LINEAR SOBRE ESTRATÉGIA EMPRESARIAL PELO PRISMA DACOMPLEXIDADE}

\section{Introdução}

0 recrudescimento das mudanças sociais e econômicas, tornou o ambiente organizacional imprevisível e conflitante com as estratégias tradicionais, passando a ocorrer processos dialéticos entre as dinâmicas do passado, presente e futuro das organizações. Quando se trabalha a estratégia, tem-se presente a consciência adaptativa aos novos paradigmas para se atingir os objetivos da complexidade e competitividade, cujo ambiente tornou-se como algo imprevisível. As estratégias passaram a ser repensadas a partir de ferramentas que permitissem a revisão e adaptação em acordo com as oscilações do ambiente (WITTMANN, 2008).

Ferramentas administrativas, baseadas em pressupostos lineares do passado, não mais atendem adequadamente a ambientes dinâmicos e complexos. 0 declínio dos velhos conceitos e ferramentas, para definição e implementação de estratégias baseados em princípios lineares, ocasionaram a busca por um novo paradigma no qual passou a ser imprescindível a aproximação dos pesquisadores com o trabalho dos estrategistas das organizações, passando a compreender a relação entre as práticas gerenciais e o desempenho global das organizações como indissociáveis, correlacionados e interdependentes (DOZ e PRAHALAD, 1991 e 1988).

Na visão de Minzberg (2004) as definições estratégicas precisam ter ênfase contingencial permitindo a flexibilidade para criar soluções em ambientes dinâmicos. Senge (2002, p. 80) critica a elaboração de estratégias de base meramente racional e linear nas quais "a realidade é feita de círculos, mas nós só vemos linhas retas, e é aí que começam nossas limitações ao raciocínio sistêmico". Raciocinar linearmente parte da visão estática do processo que segue uma ordem pré-determinada de começo, meio e fim. Tal forma de pensamento descarta as inter-relações e a interação e interdependência entre os componentes do sistema. A incapacidade organizacional de unir às diversas áreas, funções e talentos para solução dos desafios do ambiente, cria a necessidade de fórmulas estabelecidas, receitas das quais esperase reações previsíveis, as quais nem sempre ocorrem (SENGE, 2002).

Considerando a visão da estratégia como um processo dinâmico Mintzberg; Ahlstrand e Lampel (2000) argumentam que existe uma diferença entre a estratégia que se pretendia $\grave{a}$ priori e a estratégia implementada que, devido à dificuldade de previsão de cenários futuros, dificilmente a estratégia aplicada é a estratégia previamente definida. Significa dizer que não existe a estratégia ótima ex-ante e ações bem sucedidas em uma organização aplicadas a situações ou organizações distintas que trarão resultados diferentes dos obtidos na estratégia que foi eficiente e eficaz em outro ambiente. Mesmo quando uma receita for eficiente e eficaz em uma situação ou ambiente, é necessário a compreensão do contexto no qual essa ocorreu considerando o ambiente interno e externo à organização e perceber a existência de diferentes parâmetros competitivos.

A estratégia na visão tradicional alinha-se com a continuidade e não com os processos dinâmicos, nos quais a mudança é a tônica. Em contextos emergentes elaborar e aplicar a estratégia é administrar a mudança tendo em vista as adaptações necessárias às mudanças (MINTZBERG, 2004). A luz da teoria da complexidade, o pensamento científico contemporâneo esteve frente a mudanças na lógica do pensamento baseado em supostos lineares trazendo à tona a incoerência dos métodos de pesquisa cartesianos para explicar os fenômenos naturais e sociais.

O pensamento sistêmico e os constructos, que envolvem a teoria da complexidade, mudaram a forma do pensar científico formando um novo modelo perceptivo da realidade e da forma de conhecer e de se fazer ciência. A visão da interdependência e integração entre as partes afetou 
a ciência mudando o paradigma científico e com ele o fazer científico, na qual as formas lineares e cartesianas de pensamento passaram a ser vistas como insuficientes para responder às crescentes indagações de um mundo dinâmico e complexo. A partir desta visão, inicia-se a ruptura com paradigmas mecanicistas e a moderna ciência passa a compreender os elementos naturais e sociais como integrados e interdependentes, indo além da visão na qual as propriedades do todo seria a simples soma das partes (CAPRA, 1996; 2002).

A complexidade passa a ser observada a partir de mudanças na concepção do pensamento estratégico considerando características baseadas em dinâmicas não lineares, a exemplo da ambiguidade, reconstrutividade e caos estruturado. 0 ambiente - interno e externo comporta características peculiares das partes de um todo inter-relacionado que absorvem e transferem recursos que embasarão suas estruturas, estratégias e competitividade. 0 olhar sobre esse ambiente complexo passa a ser multidisciplinar, não sendo possível observá-lo como algo estável e planejado. A compreensão do futuro passa a ser possível se a empresa compreender-se como parte de um todo, mas ao mesmo tempo como um todo que emana influências e que possui uma razão de existir dentro ambientes autopoiéticos.

0 presente ensaio teórico consiste em uma reflexão comparativa entre as estratégias empresariais baseadas em pressupostos lineares, focados em planejamentos disciplinares ou estratégias rigidamente estruturadas e a visão de estratégias baseadas em processos sistêmicos e complexos. A visão complexa propõe um novo paradigma a partir de análises do ambiente e suas inter-relações analisadas a partir da teoria da complexidade, transmitindo uma compreensão diferenciada das estratégias rígidas e lineares. Em modelos complexos as empresas passam a ser geridas pelo planejamento das ações futuras levando em conta aspectos multifuncionais, multilaterais e multidisciplinares provindos de alterações de suas relações internas e externas.

Este trabalho foi estruturado iniciando com a revisão e elaboração de um conceito de estratégia, seguido por uma visão da relação entre estratégia empresarial e complexidade. Nas considerações finais é sugerida uma teoria integradora entre as visões que norteiam a elaboração das estratégias, argumento fortalecido pela VBM (Visão Baseada no Mercado) de Porter e a VBR (Visão Baseada em Recursos) de Penrose.

\section{Estratégia}

Nos estudos administrativos o conceito de estratégia foi desenvolvido por autores como Chandler (1962), Andrews (1971), Kotler, (1975), Ansoff (1977), Chaffee (1985), Mintzberg e Quinn, (1992), Ansoff e McDonnell (1993), Stoner e Freeman (1995), Porter (1996), Dyer e Singh (1998), Montgomery e Porter (1998), Barney (2002). Embora os primeiros estudos na área de Administração têm início na segunda metade do século XX,, a origem do conceito de estratégia nos remete a Grécia antiga e deriva do vocábulo stratègós, que resultou da associação das palavras stratos (exército) com ag (liderar). Estratégia, em sua concepção significa 'a função do general do exército frente às tropas" e que Péricles, desde antes da Era Cristã (450 A.C.), a identificou como um conjunto de habilidades gerenciais: administração, liderança, oratória e poder. Um século mais tarde Platão, (por volta de 350 A.C.) no seu diálogo político usou o vocábulo estratégia para tipificar o conhecimento de como fazer a guerra. A visão histórica aponta para a origem do termo entre os militares e referia-se às funções do general no comando do exército, o que resultou na utilização do termo como 'a arte de um general', que significa o conjunto de habilidades psicológicas, técnicas e comportamentais com as quais o comandante dirigia sua tropa. No período de Alexandre (330 d.C.), estratégia significava a habilidade de utilizar as forças para subjugar opositores e possibilitar a influência e controle do dominado (MINTZBERG e QUINN, 1992). 


\section{UMA VISÃO NÃO-LINEAR SOBRE ESTRATÉGIA EMPRESARIAL PELO PRISMA DACOMPLEXIDADE}

Nos estudos econômicos até o século XIX o pensamento estratégico aplicado às transações econômicas apresentava-se de forma limitada (GHEMAWAT, 2002). Apesar da intensificação da competição em certos ramos de negócios as empresas aparentavam não sofrer as conseqüências da competição (HITT; IRELAND e HOSKISSON, 2003). Durante este período, o pensamento econômico centrava seus estudos na concorrência perfeita. Somente com o advento dos trabalhos de Antonie Cournout, em 1838, com as ideias sobre monopólio e lucratividade nas indústrias, é que se passou a entender que havia diferentes níveis de competitividade em diferentes mercados tornando a utilização de estratégias específicas e relevantes para cada mercado uma ação necessária para a consecução dos objetivos organizacionais (GHEMAWAT, 2002). Entretanto, mesmo em mercados em competição perfeita, nos quais as empresas possuem acesso aos mesmos tipos de informações, provavelmente cada empresa reage de forma diferenciada em virtude da concorrência. Em uma indústria, as ações de uma empresa não são independentes das ações das demais, pois as ações de uma empresa afetarão as demais e também outros tipos de industrias correlacionadas (CARVALHO e LAURINDO, 2003).

A utilização do termo no meio empresarial se consolida a partir de 1944 com a publicação do trabalho de Von Neumann e Morgenstern que descreveram a hoje famosa teoria dos jogos. A utilização das teorias de Neumann e Morgenstern iniciou na microeconomia quando se estudavam as estratégias empresariais e a consequente reação dos concorrentes e consumidores às estratégias implementadas. Este construto teórico mostrou-se útil para identificar estratégias ideais de negociação para delinear estratégias prováveis e para o desenho das posturas de negociação que aumentassem a probabilidade de atingir os objetivos organizacionais (FIANI, 2006).

Alguns autores se valeram da teoria dos jogos para conceituar a estratégia como um conjunto de áreas específicas no que tange a produtos e mercados. No entanto, outros autores preferiram defini-la no sentido militar, considerando-a como o campo de atuação da empresa. Esta visão dual fez com que Ansoff formulasse uma definição composta que abrangesse por completo o conceito, pois ambos significados eram complementares. 0 primeiro, considerado por ele como estratégia pura, compreende uma manobra ou um conjunto de manobras de uma empresa na qual produtos e mercados estão claramente delineados. No segundo conceito, que pode ser denominado estratégia maior ou mista, fica intimamente ligada a situações determinadas a partir de uma regra estatística de decisão para auxiliar na definição da estratégia pura a ser adotada em uma dada situação (ANSOFF, 1977).

Na visão de Bethelem (2003) a área de estratégia, no que tange a sua conceituação, formulação, planejamento, processo e implantação, tem sido amplamente pesquisada nos últimos 40 anos, o que gerou vultuoso material, contudo permanece a característica difusa e da acentuada controvérsia sobre este tema. Embora haja certa dispersão quanto ao conceito de estratégia podemos sintetizá-lo como a capacidade da empresa de pensar, planejar e implementar de forma contínua e sistemática ações presentes e futuras que garantam a sustentabilidade econômica, social, cultural e ambiental da organização considerando as condições internas e externas da organização.

Apesar da antiguidade do termo e de seu largo uso no campo administrativo, as definições para estratégia não podem ser consideradas únicas, causando uma diversidade de conceitos para a mesma lógica de pensamento. Autores como Mintzberg e Quinn, (1992) e Chaffee (1985) observam a inexistência de uma definição universalmente aceita para a estratégia, devido à aplicação do termo ser diversa tanto no meio acadêmico como empresarial. Entre os 
pesquisadores e executivos que utilizam o termo de forma corrente existem, por exemplo, os que incluem metas e objetivos como integrantes da estratégia e outros que distinguem claramente entre as estratégias e os objetivos (Quadro 1).

\begin{tabular}{lc}
\hline \multicolumn{1}{c}{ CONCEITO } & AUTOR \\
\hline Escolha de metas e objetivos de longo prazo de uma empresa e a determinação & \\
de cursos de ação e alocação de recursos necessários para alcançar estas & Chandler, (1962) \\
metas. &
\end{tabular}

A ciência e arte militar de aplicar a força armada de uma nação para assegurar as metas definidas pelas lideranças da nação. Por essa forma de ver o uso da estratégia deixa-se de considerar o plano de ação para atingir metas.

A estratégia corporativa, na visão do autor, é o padrão, objetivos, propósitos ou Andrews (1971) metas, políticas essenciais e planos para alcançar aquelas metas descritos de forma que tornem claro o negócio da empresa que é ou pretende ser e o tipo de empresa que é ou deveria ser.

\begin{tabular}{|c|c|}
\hline $\begin{array}{l}\text { A estratégia pura compreende uma manobra ou um conjunto de manobras de } \\
\text { uma empresa na qual produtos e mercados estão claramente delineados. A } \\
\text { estratégia maior ou mista se aplica a situações determinadas a partir de uma } \\
\text { regra estatística de decisão para auxiliar na definição da estratégia pura a ser } \\
\text { adotada em uma dada situação. }\end{array}$ & Ansoff (1977) \\
\hline $\begin{array}{l}\text { A estratégia constitui-se em um conjunto de regras de tomada de decisão para } \\
\text { orientação do comportamento de uma organização e representa os meios para } \\
\text { se atingir os objetivos que a empresa tenta alcançar. }\end{array}$ & $\begin{array}{c}\text { Ansoff e McDonnell } \\
\text { (1993) }\end{array}$ \\
\hline $\begin{array}{l}\text { A estratégia pressupõe a definição dos objetivos da organização e constitui-se } \\
\text { em regras para tomada de decisão da cúpula da organização que não podem } \\
\text { ser delegadas aos níveis operacionais. Tais decisões ocorrem em condições de } \\
\text { risco, incerteza e desconhecimento parcial dos resultados que serão } \\
\text { alcançados. }\end{array}$ & $\begin{array}{c}\text { Stoner e Freeman, } \\
\text { (1995) }\end{array}$ \\
\hline
\end{tabular}

A estratégia significa fazer escolhas de posicionamento competitivo e sua essência é decidir o que fazer, ou seja, na sua visão a estratégia deve ser arquitetada conjugando valor, posição única e valiosa, escolhas de posicionamento competitivo, integração e adaptação de atividades; somente com a otimização desses parâmetros a estratégia será capaz de trazer competitividade e sustentabilidade, proporcionando uma combinação única de valor.

Quadro 1: conceitos de estratégia

Fonte: elaborado pelos autores

Montgomery e

Porter (1998)

A interpretação dos autores relacionados no Quadro 1, indica que a estratégia, mesmo em diferentes concepções organizacionais, a mesma está relacionada a objetivos, propósitos, metas, regras, meios e planos de ação que as posicionam no mercado e melhoraram sua competitividade organizacional e operacional.

A estratégia, nesta abordagem constitui-se em uma fonte complexa de relações e inspirações que auxiliam na tomada de decisões nos diferentes níveis - estratégico, tático e operacional que levam as empresas a melhorarem suas relações competitivas de mercado.

\section{Estratégia e a Teoria da Complexidade}




\section{UMA VISÃO NÃO-LINEAR SOBRE ESTRATÉGIA EMPRESARIAL PELO PRISMA DACOMPLEXIDADE}

A formulação e análise da estratégia e de seus partícipes requer a transposição do prisma linear e reducionista para as teorias Sistêmica e da Complexidade. Impõe-se, nesta senda a lógica e utilização de visões multidisciplinares e transdisciplinares para perceber a realidade sem ser necessário reinventá-la, pois o problema está na capacidade de ser percebida em sua complexidade.

A realidade existe em sua plenitude, contudo é captada e interpretada sob o arcabouço de paradigmas, que Thomas Kuhn (2005) define como visões do mundo e que durante determinados períodos limitam nossas interpretações e significados reduzidos a partir de padrões pré-concebidos a exemplo de quebra-cabeças. Quando a observação linear prepondera, a captação da substância e da complexidade da concorrência ambiental fica comprometida, sendo ilógico conceber que a natureza do ambiente de competição empresarial não impacte o desempenho empresarial (PORTER, 2004).

Uma visão linear, aos moldes cartesianos, implica em percepções distorcidas, levando a tomadas de decisões estratégicas, táticas e operacionais equivocadas, comprometendo a sustentabilidade econômica. Pela teoria da complexidade, a percepção não linear do ambiente contrapõe-se a linearidade cartesiana, embora a existência da linearidade não possa ser excluída em absoluto da análise da complexidade. 0 prisma burocrático e mecanicista, em muitas situações, pode transmitir segurança e confiança à execução de ações ao estabelecer padrões necessários para uma compreensão e comparação completa do objeto observado, a exemplo do computador, um produto complicado dotado de alta tecnologia, mas que em sua essência é uma máquina simples em razão de sua linearidade e recursividade operacional (WITTTMANN, 2008).

A utilização dual das visões linear e complexa se justifica devido à existência de diferentes tipos de empresas que lidam em condições diversas de mercado e de tecnologia. Empresas que atuam em ambientes incertos e turbulentos necessitam de maior grau de diferenciação e seus processos são mais dinâmicos e complexos. Entretanto, aquelas que competem em ambientes lineares e estáveis permitem uma maior ênfase na utilização de processos mecanicistas e burocráticos (MORGAN, 1996). Em razão dessa presença relativa entre o mecanicismo e complexidade, as estratégias fundamentam-se em construtos lineares e não lineares para a compreensão plena dos ambientes, sendo que a estrutura será burocrática na proporção exigida pelos fatores situacionais proporcionais às características ambientais (MINTZBERG, 1995).

A empresa, em relação a ambientes complexos, opera como um sistema aberto e fechado. Esta ambivalência, aparentemente contraditória, é determinante para formatar a identidade da empresa, uma vez que ao se desenvolver internamente os recursos captados exteriormente ela os adapta às suas necessidades e molda-os conforme sua cultura, princípios e valores. Tudo que existe, inclusive as empresas, é composto por sistemas que constituem uma unidade que engloba diferentes partes e não são objetos fechados, mas entidades inseparavelmente coligadas ao ambiente que são realmente conhecidas em um determinado contexto (MORIN, 2003).

A sustentabilidade da empresa provém de sua estrutura interna e do ambiente de interrelações simbióticas que possibilitam a perpetuidade ou a descontinuidade em razão das variações ambientais internas e externas. A relação da empresa versus ambiente se dá por interações organizacionais diretas de clientes, fornecedores, concorrentes e entidades sociais e reguladoras e, num contexto mais amplo, com um macroambiente que, embora este não seja influenciado por ações e decisões diretas da empresa, afeta em suas estratégias. Segundo 
Morgan (1996) ambiente e empresas são compreendidos em estado continuado de interação e dependência mútua, cuja troca é fundamental para a sustentabilidade. Quando o ambiente é considerado de forma ampla, o que nele ocorre afeta todas as empresas, entretanto, cada uma reagirá segundo sua identidade, pois, embora o ambiente seja o mesmo, cada competidor dá sua interpretação pela criação de suas diferenciações de sustentabilidade e de oportunidades.

0 estabelecimento de uma estratégia feita, a partir de autointerpretações, impõe escolhas (PORTER e KRAMER, 2008). Contudo, compreender o ambiente sob o prisma da complexidade expõe uma mesma realidade a diferentes interpretações, que permitem, à empresa, dimensionar diferentes estratégias para criar vantagens competitivas, uma vez que, o contexto competitivo, sob o qual a empresa atua, afeta suas estratégias futura.

O prisma da complexidade sobre o ambiente auxilia a empresa assentar sua estratégia empresarial na dinâmica da concorrência competitiva. A observação do dinamismo do mercado permite que os fatos sejam compreendidos não apenas contrapondo seus opostos e tirando-se conclusões, mas entendê-los como algo em mudança continuada dinâmica e sistêmica (HAMEL e PRAHALAD, 1995).

A estratégia empresarial é construída sob uma linha temporal. A concepção da complexidade informa que voltar ao passado não é possível, como da mesma forma determinar o futuro também não é possível. 0 futuro é um tempo em aberto, incerto, imprevisível e o que se pode fazer no presente são aproximações hipotéticas baseando-se em referenciais históricos e procedimentos já conhecidos e repetidos, tentando vislumbrar o amanhã (DEMO, 2002). A empresa não desfrutará do futuro se for incapaz de imaginá-lo e nem triunfará em sua jornada sem tê-lo previsto considerando sua complexidade. A empresa não deve olhar o futuro sob um prisma estreito linear, pois mercados amadurecem, competências evoluem e somente uma visão não-linear e sistêmica sobre atos e fatos consegue captar e apreender o dinamismo necessário para a construção estratégica (HAMEL e PRAHALAD, 1995).

As empresas, por serem fenômenos complexos e paradoxais são compreendidas de maneiras diversas. As interpretações da realidade apresentam dimensões complexas que residem sobre a análise elaborada muito mais pelo olhar do observador do que de informações puras do fenômeno observado (MORGAN, 1996). Ao compreender empresas como sistemas, que ao mesmo tempo é todo e parte, pressupõe-se a existência de subsistemas. Um desses inúmeros subsistemas são os seres humanos que as formam e influenciam com seus olhares particulares do ambiente, dos processos e das escolhas estratégicas, táticas e operacionais.

O olhar do observador produz inputs e outputs para a construção da estratégia empresarial. 0 processo estratégico tende a criar conhecimento organizacional provindo do exercício do saber pensar considerando também as percepções subjetivas captadas do ambiente. Observar a lógica das coisas e surpreender lógicas nas quais não se perceberia o pensar flexível para o despertar da realidade mutável é decifrar o ambíguo e contraditório ordenando a importância dos elementos embaralhados em determinada situação para encontrar similaridades ou diferenças não aparentemente reconstruindo o conhecimento anterior e formulando perspectivas inovadoras (DEM0, 2002). Depreende-se que os processos organizacionais, no qual a estratégia se insere, não podem ser perfeitamente racionais, uma vez que as interpretações da realidade são concebidas pelos seus observadores.

Estes observadores possuem limitadas habilidades para processar informações, misturando interpretações segundo seus constructos, provocando um viés interpretativo. Razão porque, o exercício de pensar estrategicamente numa empresa tem um caráter multidisciplinar de forma a contemplar diferentes dimensões sobre fatos observados e estratégias projetadas. 


\section{UMA VISÃO NÃO-LINEAR SOBRE ESTRATÉGIA EMPRESARIAL PELO PRISMA DACOMPLEXIDADE}

Todos os elementos que embasam a construção do conhecimento empresarial, e que formarão sua estratégia, devem estar sustentados num conceito de incerteza e mudança, já que o futuro é algo inconcluso. Essa forma de construir o presente, com o olhar num futuro impermanente, embasa o caminhar de empresas visionárias (COLLINS \& PORRAS, 1995), em que a natureza duradoura e incompleta considera uma linha de tempo indefinida e mutabilidade do meio. A percepção de futuro encontra posições culturalmente diferenciadas influenciando as construções estratégicas ocidentais e orientais de forma diversa. Para os orientais, o futuro é "um fluxo contínuo de um 'presente' permanentemente atualizado, os ocidentais o vêem como uma visão sequencial de tempo, prevendo o futuro a partir de uma retrospectiva histórica do passado" (NONAKA \& TAKEUCHI, 1997, p. 32 e 33). Essas diferentes concepções importam não somente na estruturação diferenciada das estratégias empresariais de cada cultura como denotam a importância da interpretação do observador sob a realidade de seu meio.

A percepção temporal do conhecimento é inesgotável e representa uma referência para se estruturar uma caminhada na qual o conhecimento é inexaurível. Para Morin (1994, p. 260), "o conhecimento complexo não tem término, não apenas porque ele é inacabado e inacabável, mas também porque ele chega por si só ao desconhecimento. Atrás da complexidade, há o indizível e o inconcebível". 0 contexto, proporcionado pela complexidade sobre os elementos que devem permear uma análise estratégica: tempo, ambiente, observador, processos e estrutura permitem o desenvolvimento de análises da realidade multifacetada. Esta estará sendo observada, não somente por comportamentos ambivalentes, ambíguos, não-lineares, inter-relacionados, sistêmicos, mas também por diferentes concepções, uma vez que, a realidade por si só é única, entretanto, suas interpretações variarão pelas suas multiplicidades.

A estratégia e a Teoria da Complexidade remetem à necessidade de percepção da dualidade na interpretação do ambiente com vistas a consolidarem-se ações futuras. Pensar as organizações de forma cartesiana implica e em visões lineares e disciplinares que não comungam ambiente multifacetados, o que vem a ser um contrassenso do contexto de incerteza e mudanças que nos remetem a Teoria da Complexidade a ser aprofundado no item a seguir.

\section{Ambiente complexo e estratégia}

A complexidade apresenta-se na forma de um diálogo caótico, aleatório e incerto entre determinações e forças de ordem e desordem na forma de 'caos estruturado' em movimentos associados a economia, sociologia, tecnologia, mitologia e o imaginário (MORIN, 2003). É por esse olhar que a essência da formulação estratégica competitiva relaciona uma empresa com o seu meio.

Construir uma estratégia consiste em extrair elementos de diversas fontes, em que a profundidade considerada seja tão ampla quanto o que se pretende imprimir à presunção do futuro compreendido por entendimentos complexos. 0 pensamento estratégico considera realidades históricas, políticas, sociais, econômicas, ambientais e culturais, sem prescindir das turbulências associadas á visão sistêmica e complexa dos processos. Estas realidades quando entendidas pela dualidade linear e da complexidade servem como um fator de segurança ao observador, porém de relevância ínfima diante da visão complexa do presente e do futuro.

Os fatos históricos formais ou informalmente divulgados estão sujeitos a interpretações passadas e presentes, contudo ambientes futuros requerem inovação e criação a partir de incertezas e riscos. Os fatos ocorridos produziram os seus resultados também influenciados 
por um ambiente incerto, no qual acasos foram encontrados no percurso e que, em muitos momentos, não foram devidamente previstos, contudo, esses possam ser utilizados como bagagem, a complexidade do futuro requer a criação de novas fontes paradigmáticas. Ressalta-se, que a potencialidade de ocorrência de determinados fatos futuros pode não ser corretamente dimensionada, porque, em essência, pertence a uma dinâmica complexa interativa entre o todo e as partes, embora existam traços passíveis de previsibilidade ao se inter-relacionarem com o ambiente que carregam fatores inesperados.

Quando se analisam os fatos passados ou presentes, a contextualização do ambiente é fator primordial para se relativizar causas e efeitos. Toda ação tem profunda interatividade com seu ambiente, bem como com os agentes que a planejam, traçam metas e a executam. Agentes e ambiente, todavia, desviam a ação de seus fins provocando uma solução diversa da esperada, denotando um grau de imprevisibilidade do resultado para projeções de eventos futuros. A estratégia, portanto, carrega consigo a consciência da incerteza que irá enfrentar, ensejando uma aposta que requer consciência plena da sua vulnerabilidade para que planos de ações não se assentem em falsas certezas.

Por mais acurada que seja a pesquisa e a análise ambiental contextualizada no seu tempo histórico, a estratégia deve ser olhada sob múltiplos focos a partir da construção de distintos cenários, desde os mais favoráveis aos inconvenientes que provocariam situações irreversíveis e que possibilitariam, à empresa, desenhar planos contingenciais para enfrentar eventos que possam afetá-la na sua caminhada cotidiana.

Para dar suporte a essa análise ambiental, considerando o viés da complexidade, inclusive dentro de sua lógica linear, o ambiente pode ser tripartido em macro, micro e interno à empresa. Cada um desses ambientes, descritos a seguir, apresentam características distintas e que impactam sobre seus agentes e sobre o próprio ambiente de maneira diversa. 0 interrelacionamento entre esses três ambientes é constante, sendo difícil divisar claramente a influência de um sobre o outro, visto que cada um é um todo em si e ao mesmo tempo parte do outro.

\section{Macroambiente}

O macroambiente é constituído por forças demográficas, econômicas, ambientais, tecnológicas, políticas, legais e socioculturais que afetam o mercado como um todo, influenciando as ações das empresas e a sua lucratividade (KOTLER, 2000). Esses fatores constituem externalidades sobre as quais a empresa detém escassa ou nenhuma possibilidade de intervenção, porém que delineiam parâmetros para sua construção estratégica considerados por Ferraz, Kupfer e Haguenauer (1996) como fatores sistêmicos. A leitura desse ambiente tem um elevado grau de subjetividade, pois em muitos casos as análises alicerçam-se em possibilidades de ocorrência futura de forças não controláveis. A materialização das projeções destes fatores carrega um elevado nível de imprevisibilidade, uma vez que ações individuais de agentes, sejam indivíduos ou empresas, têm sua força reduzida diante de um todo amplamente complexo, dinâmico e caótico. Esse todo também é compreendido como parte de um amplo universo e, portanto, passível de sofrer influência de fenômenos isolados e totalizantes.

Um indivíduo, dependendo de sua importância num contexto histórico-temporal, pode provocar, por meio de seus atos, impactos nas partes de um sistema, influenciando-o de forma neutra, negativa ou positiva de acordo com a posição ocupada por essa parte no todo. Por estarem inseridas nesse ambiente, as empresas com suas atividades são influenciadas e inspiram, tendo impactos internos e externos (TENÓRIO, 2006), que podem, dependendo de 


\section{UMA VISÃO NÃO-LINEAR SOBRE ESTRATÉGIA EMPRESARIAL PELO PRISMA DACOMPLEXIDADE}

sua posição e poder no mercado, influenciar as partes ou o todo.

Nesta variável macroambiental, a empresa é parte integrante de um sistema econômico que favorece ou restringe a realização de seu potencial competitivo e cuja ocorrência independe de suas condutas (FERRAZ, KUPFER e HAGUENAUER, 1996). Esses fatores gerados pelo macroambiente, no qual o econômico se inclui, são dinâmicos e interagem entre si afetando os negócios de maneiras distintas e com diferentes pesos (SERRA; TORRES e TORRES, 2002). Para que a empresa possa minimizar os efeitos desses fatores imprevisíveis e involuntários sobre seu negócio e seu ambiente, deverá conceber, dentro de sua estratégia, dispositivos flexíveis para enfrentar situações de desconhecimento parcial e que deem sustentação à sua visão de futuro.

A visão de futuro projetada não deve comportar padrões de julgamento ou certezas sobre a ocorrência de oportunidades ou ameaças, nem se as consequências advindas serão melhores ou piores (ANSOFF, 1977). Assentar-se sobre certezas construídas em futuros incertos pode provocar desvios comprometedores da realidade para a sustentabilidade estratégica, embora imaginações futuras que a empresa poderá vivenciar, cenários poderão ser construídos.

Um conjunto de cenários distintos - observados ou projetados - constitui um modelo do que pode vir a ocorrer, representando retratos de cenários possíveis. Os cenários não apontariam para um caminho determinado, previsível, possível, mas um horizonte que poderia antecipar como as diversas forças e os diversos fatores externos se apresentariam nas distintas direções futuras (SERRA; TORRES e TORRES, 2002).

As observações do macroambiente e a construção de cenários - potenciais ou remotos futuros comportam um elevado nível de complexidade ao explorarem a ambiguidade, a redundância e os ruídos dos sinais de elementos que compõem esse ambiente para aprimorarem o seu próprio sistema - autoorganizador - de conhecimento. Esse conhecimento, gerado pela interpretação de informações ambientais, tem elementos de profecia que autosatisfaz a empresa que tem consigo uma forte disposição de se transformar no que deseja (NONAKA \& TAKEUCHI, 1997), impondo ao todo novos elementos que o alimentarão e provocarão no mercado adequações nos seus agentes em respostas às forças competitivas.

O ambiente empresarial não prescinde de equilíbrio, mas de um continuado estado de mudança para evoluir e manter-se competitivo. Num sistema complexo a ação e a reação de uma parte são dependentes do estado de outras partes e do todo, gerando intermitentes trocas de inputs e outputs entre agentes e meio. Porter (1989) referenda a dinâmica do ambiente pela capacidade de entender e gerenciar a mudança e de agir pela criação do conhecimento no qual empresas e economias floresçam devido às pressões, desafios e novas oportunidades. Esta reconstrutividade ocorre não em consequência de um ambiente tranquilo e sim da mudança pela qual as empresas tem o poder de determinar seu sucesso competitivo em longo prazo em virtude da possibilidade da criação do conhecimento e da capacidade de agir como resultado de um processo localizado que determina o sucesso competitivo.

Os elementos analisados, pela construção de cenários futuros, são categorizados internamente como oportunidades e ameaças que representam para a empresa vantagens e desvantagens competitivas. Estas percepções propiciam estruturar formalmente ações passíveis de serem implementadas diante das ocorrências imaginadas, minimizando seus efeitos e não prejudicando a rentabilidade da empresa e nem comprometendo sua sustentabilidade econômica. 


\section{Microambiente}

O microambiente empresarial compreende os agentes que, com suas ações, reações, omissões, desejos, necessidades, poder e força, impactam diretamente sobre cada um dos competidores de uma indústria em um dado ambiente. A análise desse ambiente é mais concreta e, mesmo envolvendo um elevado nível de complexidade, permite que sejam utilizados elementos burocráticos e lineares como séries temporais, para embasar ações que possibilitam a estratégia competitiva prosperar no futuro gerando riqueza interna para a empresa e para a sociedade.

Forças impostas pelo macroambiente podem desequilibrar estruturalmente o microambiente e o ambiente interno de uma empresa. Em reação, a empresa considerará a disponibilidade de recursos sob seu gerenciamento (MINTZBERG et al, 2003). Recursos esses pré-existentes na estrutura organizacional e adaptados à nova realidade, ou projetados e resguardados na elaboração estratégica sobre a previsibilidade de ocorrências futuras por meio da apreensão de conhecimento passado, entendimento dos eventos presentes e percepção dos movimentos recorrentes para imaginar um 'como' futuro.

Como contribuição ao estudo do microambiente, a análise das Forças Competitivas rivalidade entre as empresas, poder de negociação de compradores e fornecedores, ameaça de produtos substitutos e de novos entrantes - permite que a empresa encontre uma posição dentro do mercado de atuação em que possa se defender contra forças competitivas externas, influenciando-as a seu favor (PORTER, 2004). Igualmente, permite observar oportunidades e ameaças latentes ou remotas, proporcionando análises das forças e fraquezas no ambiente interno que poderão impactar favoravelmente ou não na capacidade competitiva da empresa.

Compreendendo esta análise ambiental como um sistema complexo, depreende-se que todas as empresas - partes de um ambiente - realizam os mesmos estudos. Porém essas chegam a conclusões diferentes, não apenas pelos fatos observados conterem ambiguidades e ambivalências, mas, principalmente, porque cada olhar é moldado por uma cultura própria provinda de princípios internos arraigados construídos pelos fundadores, influenciados não apenas pela individualidade humana, mas pelas circunstâncias do meio. Segundo Weber (2001, p. 35), deve "ser uma das primeiras tarefas da investigação [...] analisar todas as influências e relações casuais que possam ser explicadas satisfatoriamente em termos de relação ao meio ambiente", considerando inseridos nesse ambiente seus agentes e suas crenças. Ratificam-se estas afirmações com palavras de Porter e Montgomery (1998) que preceitua que a história social e política influenciam nas habilidades e na estrutura institucional dentro da qual a competição se processa. Os fatores culturais moldam o ambiente competitivo e este representa um sistema interativo no qual as partes se reforçam se retroalimentando. A construção estratégica selecionará posições específicas, estabelecendo critérios de diferenciação que descreverão como empresas diferem em ambientes aparentemente semelhantes e obtêm vantagem competitiva (MINTZBERG et al, 1998).

\section{Ambiente interno}

Embora o ambiente interno esteja contido na análise microambiental, cabe uma atenção diferenciada sobre os agentes que o compõe. Em última análise uma empresa não é apenas um ente jurídico ou uma estrutura física, mas é uma comunhão de indivíduos com propósitos de gerar riqueza para a empresa, para si e para sua cadeia de valores. A diversidade interna de uma empresa corresponde à variedade de individualidades e complexidades ambientais que permitem que a empresa enfrente os desafios impostos pelo seu meio (NONAKA \& TAKEUCHI, 1997). 0 ambiente interno, considerado sob o prisma da complexidade e concebido como um sistema aberto e fechado, processa internamente informações colhidas no meio com o intuito 


\section{UMA VISÃO NÃO-LINEAR SOBRE ESTRATÉGIA EMPRESARIAL PELO PRISMA DACOMPLEXIDADE}

de resolver problemas ou adaptar-se as oportunidades observadas num ambiente em constante transformação. Há, nesse processo, criação de novos conhecimentos e informações que também serão entregues ao mercado, redefinindo novas ameaças e oportunidades para o todo, recriando, dessa forma seu meio (WITTMANN, 2008).

A empresa gera conhecimentos, serviços e produtos processando materiais e insumos equacionando-os pelo reforço de sua identidade. Essa conectividade é realizada pelos agentes internos baseando seus comportamentos em princípios e códigos de condutas formais e informais da empresa imputando as análises realizadas e as decisões tomadas a partir de suas concepções (ANSOFF, 1977).

0 construto organizacional, provido das interpretações dos agentes que formam a empresa, depende menos das informações e dados que o embasam e mais da forma como está estruturado o modo de pensar, ou seja, é preciso conceber que é o indivíduo - agente interno - que dá unidade e invariância a uma pluralidade de processos e procedimentos e que avalia as potencialidades e estabelece as interconexões com o meio. Infere-se o pensar do indivíduo em sua concepção complexa (MORIN, 2003) como personagem primordial do ambiente empresarial e do mercado.

Todos os insumos desenvolvidos internamente dentro do processo de auto-organização concebido por um sistema fechado permitem reconhecer que "todo conhecer é um fazer daquele que conhece, ou seja, que todo conhecer depende da estrutura daquele que conhece" (MATURANA \& VARELA, 2002, p. 40), sendo indissociáveis as ações dos indivíduos que formam a empresa das ações que essa elabora para a sua sobrevivência. A competição estabelecida no mercado é sustentada pela coesão das estratégias num objetivo comum reforçando processos de identidade.

Após estas análises do ambiente complexo e estratégia, envolvendo análises do macroambiente, microambiente e ambiente interno, nos leva a aprofundar no item seguinte a aplicabilidade da Teoria da Complexidade à estratégia.

\section{Teoria da Complexidade aplicada a estratégia}

O ambiente competitivo, com o aumento do número de empresas concorrentes associado a um contexto incremental de aceleração das mudanças, impulsiona o desenvolvimento econômico e introduz novas tecnologias. Igualmente, projetam-se novas necessidades tornando serviços e produtos mais voláteis tanto nas suas formas de desenvolvimento, de marketing e de produção, como na de distribuição e consumo formando processos de retroalimentação.

A base para a ciência cartesiana e linear foi o positivismo considerando como pensamento paradigmático que influenciou o pensar científico, tendo como base os trabalhos de Augusto Comte (1995). O autor desenvolveu o pensamento positivista a partir das ideias sociológicas do iluminismo, da crise moral e social do final da idade média e do surgimento da sociedade industrial marcada pela Revolução Francesa. 0 positivismo teve seu apogeu e crise durante os séculos XIX e XX, no entanto ainda influencia as organizações e o pensamento da sociedade ao estabelecer a possibilidade de explicação dos fenômenos naturais e sociais por relações perfeitas de causa e efeito.

A superespecialização fragmentou o mundo em 'pedaços' e impossibilitou o aprendizado a partir da complexidade dos fenômenos no momento em que as partes que constituem um todo passam a ser consideradas interdependentes, integradas, inseparáveis e interativas como a economia, a política e sociologia. Entender o mundo pela visão atomística ainda é 
ensinado na escola primária pela conversão do complexo no simples. Nestas condições os jovens perdem a capacidade do entendimento da complexidade, desprezando o todo para perceberem as partes e estas se consolidarem em processos lineares. Entretanto, o século XX marca a crise do paradigma da ordem, simetria, regularidade e adequação das capacidades intelectuais às coisas, causada por reflexões sobre a forma de pensar da ciência linear e cartesiana que evidenciava suas limitações e fragilidades para entender os fenômenos complexos.

A crise se originou nos estudos de física do começo do século XX como a Teoria Geral da Relatividade de Einstein a partir da qual a noção de tempo e espaço, postulados por Newton, perdem a razão de existir. A teoria da incerteza de Heisenberg e as estruturas dissipativas de Prigogine reabilitam a noção do caos, da irreversibilidade dos processos, do indeterminismo, do observador e da complexidade. 0 universo de teorias repercute em outras ciências desde as naturais e exatas até as ciências humanas e sociais trazendo a complexidade à categoria de paradigma (NEVES e NEVES, 2006).

A estratégia empresarial, por conseguinte, busca novas formas de operacionalização abandonando métodos baseados em fontes históricas buscando novos conceitos a partir de ambientes futuros, nos quais a complexidade passa a ser o alvo interpretativo. Como bem dizem Ferraz, Kupfer e Haguenauer (1996), a avaliação da competitividade empresarial está baseada na capacidade das empresas em formularem estratégias futuras que lhe possam dar sustentabilidade e para as quais a eficiência e o desempenho são apenas indicadores passados que não dimensionam a valorização da empresa no futuro, pois são estáticos e, portanto, contrariam ambientes complexos. Esses, quando analisados, permitem um melhor conhecimento do todo, alterando as atividades presentes em contínua percepção com o futuro, gerando riqueza corporativa e social.

Não é possível competir sem conhecer a empresa, em qual ambiente competitivo atua e como será seu ambiente futuro. Essas percepções podem ser obtidas por meio de análises nas quais se "estabelece uma postura em relação ao ambiente, lidando com fatos, idéias e probabilidades" (LOBATO, 2002, p. 58). Entretanto, a estrutura do ambiente e dos seres que o integram transmitem complexidades que não podem ser compreendidas apenas linearmente ou somente de forma sistêmica. É preciso conceber além das inter-relações existentes entre as mais diversas situações observáveis no mercado e nas empresas o caráter ambíguo e ambivalente dos fatos, ou seja, compreendendo as relações por meio da teoria da complexidade. 0 mundo em que se vive e do qual se é parte integrante e influente deve ser compreendido e interpretado como um processo complexo, algo não totalmente aleatório, nem tão somente complicado (DEMO, 2002).

A complexidade pressupõe um ambiente paradoxalmente caótico e estruturado. Embora compreende-se o caótico no sentido de apresentar propriedades não-lineares e com dinâmicas ambíguas e ambivalentes, o mesmo pode ser visto na forma de uma estrutura passível de divisar ordem junto à desordem. Conhecimento desta ambiguidade é importante no momento da formulação de estratégias empresariais, pois este a influenciará proporcionando um novo senso de direção, de significados novos e uma forma diferente de pensar estrategicamente (NONAKA e TAKEUCHI, 1997).

Igualmente, a formatação de uma estratégia empresarial, sob o prisma da complexidade, permite compreender que as partes formam uma hierarquia convergente, na qual há partes essenciais não substituíveis. Essa percepção transposta para uma estruturação estratégica informa que para ser uma empresa competitiva é necessário buscar ativa e continuamente "a criação de novas fontes internas de vantagens em torno de suas competências essenciais" 


\section{UMA VISÃO NÃO-LINEAR SOBRE ESTRATÉGIA EMPRESARIAL PELO PRISMA DACOMPLEXIDADE}

(KOTLER, 1997, p. 318), em que a criatividade, tanto para encontrar caminhos de percepção da realidade, como para gerar inovações origina-se num sistema em constante amadurecimento e, portanto, não linear.

Organizações que resistem melhor às transformações do mercado são aquelas que possuem forte identidade, abertas ao meio externo com grande capacidade de aprender com as novas circunstâncias pela entrada de novos inputs. A nova conduta para que as organizações se mantenham competitivas, no cenário da globalização, inclui a capacidade de gerenciar adequadamente o conhecimento. Trabalhando na forma de um sistema aberto e fechado, no qual os indivíduos adquirem maior autonomia na tomada de decisões, a organização pode contribuir para a maior flexibilidade, criatividade e capacidade de aprendizagem (CAPRA, 2002).

A não linearidade, conjunto de processos reguladores fundamentados em múltiplas retroações é outra característica de um sistema complexo (MORIN, 2003). Nessa percebe-se a causa atuando sobre o efeito e o efeito sobre causa reflexivamente, cujo ambiente gera informações parciais ou totais, importantes ou desnecessárias à empresa, ao mesmo tempo em que a empresa lhe entrega insumos que também a influenciarão tanto nas partes como no todo. Considerando que o todo e suas partes formam um sistema, qualquer alteração nesse, independente de sua dimensão, acarreta mudanças no todo (MARCHI e WITTMANN, 2008) refletindo nas intenções estratégicas. A essência de uma estratégia empresarial eficiente não é localizada na estrutura dos produtos nem nos mercados, mas se encontra na dinâmica de comportamentos (NONAKA \& TAKEUCHI, 1995). Essa afirmação reforça a conveniência de apreender a complexidade do mercado e de seus agentes por meio de análises não lineares para compreender as incertezas já que o ambiente torna-se mais impreciso em realidades desconhecidas, que Mintzberg (1995, p. 141) expressa da seguinte forma:

em um ambiente estável, a organização pode predizer suas condições futuras e, com isso, se mantidas todas as outras condições iguais, pode facilmente isolar seu núcleo operacional e ali padronizar as atividades isto é, estabelecer normas, formalizar trabalho, planejar ações - ou em seu lugar, talvez padronizar habilidades [...] enfrentando fontes incertas de suprimentos, demandas imprevisíveis de clientes, alta rotatividade de pessoal, condições políticas instáveis, ou rápidas mudanças tecnológicas (do conhecimento), a organização não consegue predizer seu futuro e, assim, não pode confiar na padronização para coordenar. Ela deve [...] utilizar um mecanismo de coordenação mais flexível e menos formal.

Num ambiente sistêmico há relações dinâmicas entre empresas, contudo cada empresa se distingue por ser única em sua identidade e, mesmo como parte da identidade de conjuntos maiores, não perde suas características essenciais. Subjetivamente toda empresa é um ser individual com personalidade própria que denota condições particulares e distintivas que lhe imprimem identidade. Identidade que não pode ser considerada como um fator de isolamento, algo separado e incomunicável, mas como um elemento inerente que carece de complemento e de atualização para manter-se equilibradamente no seu próprio horizonte.

A identidade constitui dependência negociada no qual o outro não é excluído, mas necessário à convivência e, embora possa haver relações de dominação conforme a estruturação do ambiente, estas não ocorrem de forma absoluta, pois sempre haverá oportunidades para distinguir-se aproveitando vantagens competitivas que lhe são singulares. A não linearidade 
implica equilíbrio em desequilíbrio, mudando não de forma linear, previsível e controlada, mas de modo criativa, surpreendente e arriscada. Vale ressaltar ainda a noção de inovação compreendida como a geração de uma ideia ou invenção em algum negócio ou aplicação útil e, que oriundas dos usuários, clientes, fornecedores, para uma ampla rede de relacionamentos que envolvem a organização (VON HIPPEL, 1988).

A complexidade associada à estratégia empresarial apresenta características reconstrutivas que preconizam que a vida não é matéria nova, mas um modo novo de organização da matéria. Numa nova organização se reencontram os elementos que constituíram a estrutura antiga ao mesmo tempo em que se descobrem processos recentes que antes não existiam (DEM0, 2002). Essa reconstrutividade dimensiona a importância que fatos históricos produzidos pela empresa e pelos seus ambientes têm para a estruturação organizacional, solidificando engrenagens que produzem ações e retornos no presente, estabelecendo inputs que permitirão imaginar como o futuro será considerando, nessa construção, a análise sistêmica de organização do meio, cujo passado, presente e futuro estão relacionados por processos de autoreconstrução.

Sendo a estratégia empresarial um conjunto de meios que uma empresa utilizará para alcançar seus objetivos (SERRA; TORRES e TORRES, 2002), observar a sua estruturação sob o prisma da complexidade, permite compreender os processos por seus componentes formalizáveis e não formalizáveis, controláveis e incontroláveis e rotas previsíveis e imprevisíveis. Essas características imprimem uma dimensão superior e abrangente, agregam informações diversificadas e possibilitam interpretações múltiplas e adaptáveis à realidade pontual por meio de contextualizações. Essas características, a partir de sistemas complexos, auxiliam a empresa extrair recursos - como num sistema aberto e fechado - para embasar sua estratégia e projetar suas ações estratégicas, táticas e operacionais, tendo como principal objetivo desenvolver vantagens competitivas para gerar riqueza e perpetuar-se.

\section{Considerações finais}

A partir dos autores revisados neste estudo pôde-se observar convergências importantes para ampliar os estudos sobre o tema complexidade e estratégia, sendo que com a visão aqui desenvolvida entendeu-se que: a estratégia constitui-se em uma fonte complexa e interdependente de relações e que auxiliam na tomada de decisões nos diferentes níveis da organização visando a vantagem competitiva. A relação observada, a partir dos autores revisados, entre Estratégia e Teoria da Complexidade é obtida na aproximação de visões diferentes sobre a estratégia, integradas a um modelo dinâmico e sistêmico no qual a utilização de diferentes visões olhando de dentro para fora e de fora para dentro a organização permitem alcançar o gerenciamento sistêmico. Pode-se entender que pensar no gerenciamento cartesiano, baseado em modelos estáticos, não é mais válido no contexto competitivo e a palavra mais importante para definir a estratégia nesta visão é adaptação.

Estratégias empresariais aplicadas sob a visão dinâmica e complexa da realidade possibilitam que a empresa aprenda se autorecrie a partir de ambientes autopoiéticos. A autopoiese permite a autocriação de conhecimentos que são desenvolvidos pelas relações sistêmicas entre as partes e o todo num processo contínuo de evolução. Neste sentido há uma contraposição aos paradigmas cartesianos baseados em pressupostos lineares e mecanicistas de relações de causa e efeito, sem ater-se à teoria da complexidade.

0 conhecimento organizacional, gerado no ambiente interno de uma empresa, ocorre pela intensiva troca que ocorre na interação empresa-ambiente fazendo com que o conhecimento gerado, seja considerado um insumo que abastece a elaboração das estratégias organizacionais. 0 mesmo também serve como referência para que o meio também se atualize 


\section{UMA VISÃO NÃO-LINEAR SOBRE ESTRATÉGIA EMPRESARIAL PELO PRISMA DACOMPLEXIDADE}

e se modifique promovendo mudanças para que o fluxo de vida dos sistemas econômicos siga se transformando e evoluindo num ciclo contínuo e ininterrupto de mudança a partir de novos construtos organizacionais.

As estratégias desenvolvidas pelas empresas para enfrentar o ambiente competitivo não somente lhes asseguram sobrevivência, mas também permitem que o meio evolua e permaneça dinamicamente ativo interferindo nas empresas e sendo por estas influenciadas. Como a estratégia pode ser concebida como um impulso mediador entre a organização e seu meio, as interrelações produzirão insumos que permitirão inovações, que são os agentes primários da mudança nos sistemas econômicos. Empresas, que se mantêm interconectadas com seu ambiente e que estejam capacitadas para interpretar os elementos complexos do meio, absorvem informações significativas e geram conhecimentos organizacionais e capazes de reagir às transformações.

Resta identificar as ferramentas adequadas para a formulação de estratégias que contemplem a complexidade, embora como foi analisado neste artigo, sem prescindir de formar lineares e neste particular o planejamento estratégico ou suas microestruturas como matriz SWOT, na utilização da análise interna e externa da organização. Tampouco as teorias que envolvem a relação entre mercado e estratégia como a VBM (Visão Baseada no Mercado) de Michael Porter ou as teorias que envolvem a relação entre as capacidades da empresa e a estratégia como a VBR (Visão Baseada em Recursos) advinda das ideias inovadoras de Penrose são suficientes para elaborar estratégias eficientes e eficazes, pois acabam sendo utilizadas isoladamente.

Sugere-se o desenvolvimento de uma teoria integradora entre estas visões que poderiam definir estratégias a priori mais efetivas. A visão integrada da empresa e suas capacidades com o mercado, no entanto ainda não seria suficiente, pois a dinâmica do ambiente, no qual ocorre à estratégia, impõe a necessidade de realizar adaptações ao longo do processo para moldar a estratégia definida a priori fazendo desta uma efetiva consecução dos objetivos organizacionais.

O pensamento estratégico é a forma mais adequada para definir as diretrizes organizacionais, pois supera a linearidade do planejamento estratégico pelo estímulo a intuição e criatividade que possibilita a flexibilidade e adaptabilidade da organização ao ambiente (MINTZBERG, 2004). Esta forma de definir a estratégia necessita muito mais que formulação de objetivos, metas e planos, mas supõe o desenvolvimento da capacidade de visão sistêmica da empresa e seu ambiente. Para alcançá-la exige das empresas mais do que recursos materiais exige capacidades de extrapolar a objetividade e o cartesianismo atingindo graus de maturidade no qual a visão da estratégia passa a ser o cerne da empresa superando os recursos materiais em importância tornando-se o determinante de sucesso no ambiente competitivo.

\section{Nota:}

${ }^{1}$ Sustentabilidade é compreendida neste trabalho como a capacidade da empresa manter-se no mercado, ou seja, sustentar-se. 0 termo é utilizado aqui desprovido de relação com as questões ambientais.

\section{Referências}


ANDREWS, K.R. The concept of corporate strategy. Homewood, IL: Dow Jones-Irwin, 1971.

ANSOFF, H. I. Estratégia empresarial. São Paulo: McGraw-Hill, 1977.

ANSOFF, I. H.; MCDONNELL, Edward J. Implantando a administração estratégica. 2. Ed. São Paulo: Atlas, 1993.

BARNEY, J. B. Gaining and sustaining competitive advantage. $2^{\mathrm{a}}$ ed. New Jersey: Prentice Hall, 2002.

BETHLEM, A. Evolução do pensamento estratégico no Brasil: textos e casos. São Paulo: Atlas, 2003.

CAPRA, F. A teia da vida: uma nova compreensão científica dos sistemas vivos. São Paulo: Cultrix, 1996.

CAPRA, F. As conexões ocultas: a ciência para uma vida sustentável. São Paulo: Cultrix, 2002.

CARVALHO, M. M. de e LAURINDO, Fernando J. B. Estratégias para competitividade. São Paulo: Futura, 2003.

CHAFFEE, E. E.. Three models od strategy. Academy of Management Rewiew, vol. 10, n. 1, 8998, 1985.

CARVALHO, M M.; LAURINDO, F. J. B. Estratégias para competitividade. São Paulo: Futura, 2003.

CHANDLER, A. D. Strategy and structure: chapters in the history of the industrial enterprise. Massachusetts, USA: The M.I.T. Press, 1962.

COLLINS, J.; PORRAS, J. Feitas para durar. São Paulo: Rocco, 1995.

COMTE, A. Discurso preliminar sobre o espírito positivo. Cultura Brasileira: São Paulo, 1995.

DEMO, P. Complexidade e aprendizagem: a dinâmica não linear do conhecimento. São Paulo: Atlas, 2002.

DOZ, Y. L.; PRAHALAD, C. K. Managing DMNCs: a search for a new paradigm. Strategic Management Journal, v. 12, Special Issue, p. 145-164, 1991.

DOZ, Y. L.; PRAHALAD, C. K. Quality of management: an emerging source of global competitive advantage? In: HOOD, N.; VAHLNE, J. E. (Eds.). Strategies in Global Competition. London: Croom-Helm, p. 345-369, 1988.

DYER, J.H.; SINGH, H.. The relational view: cooperative strategy and sources of interorganizational competitive advantage. Academy of Management Review, v 23 n 4: 660679, 1998.

FERRAZ, J.; KUPFER D. HAGUENAUER, L. Made in Brazil: desafios competitivos para a indústria. Rio de Janeiro: Campus. 1996.

FIANI, R.. Teoria do Jogos: para cursos de administração e economia. 2. ed. Rio de Janeiro: Elsevier, 2006. 


\section{UMA VISÃO NÃO-LINEAR SOBRE ESTRATÉGIA EMPRESARIAL PELO PRISMA DACOMPLEXIDADE}

GHEMAWAT, P. Competition and business strategy in historical perspective. Business History Review. Spring, v.76, n.1, p. 37-74, 2002.

HAMEL, G. PRAHALAD, C.. K. Competindo pelo futuro. Rio de Janeiro: Campus, 1995.

HITT, M. A.; IRELAND, D.; HOSKISSON, R. E. Strategic management: competitiveness and globalization. 5a ed. Ohio: Thompson, 2003.

KOTLER, P. Administração de marketing. São Paulo: Prentice Hall, 2000.

O marketing das nações. São Paulo: Futura, 1997.

Administração de marketing. São Paulo: Atlas, 1975.

KUHN, T. A estrutura das revoluções científicas. São Paulo: Perspectiva, 2005.

LOBATO, D. Administração estratégica. Rio de Janeiro: Editoração, 2002.

MARCHI, J.; WITTMANN, M.. Princípios da teoria da complexidade aplicados à gestão das organizações. In: WITTMANN, M.. Administração: teoria sistêmica e complexidade. Santa Maria: Editora da UFSM, 2008.

MATURANA, H. VARELA, F. A árvore do conhecimento. São Paulo: Palas Athena, 2002.

MINTZBERG H.; J. B. QUINN.. The strategy process: concepts, contexts and cases. Englewood: Prentice-Hall, 1992.

MINTZBERG, H.; AHLSTRAND, B e LAMPEL, J. Safari de estratégia: um roteiro para a selva do planejamento estratégico. Bookman: Porto Alegre, 2000.

MINTZBERG, H; et al. The strategic process: concepts, contexts, cases. $4^{\text {th }}$ ed. New York: Prentice Hall, 2003.

MINTZBERG, H. Ascensão e queda do planejamento estratégico. Porto Alegre: Bookman, 2004.

Criando organizações eficazes. São Paulo: Atlas, 1995.

MONTGOMERY, C. A.; PORTER, M. E. Estratégia: a busca da vantagem competitiva. 4. ed. Rio de Janeiro: Campus, 1998.

MORGAN, G. Imagens da organização. São Paulo: Atlas, 1996.

MORIN, E. A cabeça bem-feita. Rio de Janeiro: Bertrand Brasil, 2003.

Meus demônios. Rio de Janeiro: Bertrand Brasil, 1994.

NEVES, C. E. B.; NEVES, F. M..O que há de complexo no mundo complexo? Niklas Luhmann e a teoria dos sistemas sociais. Sociologias: Porto Alegre, ano 8, no 15, 2006.

NONAKA, I.. TAKEUCHI, H. Criação de conhecimento na empresa. Rio de Janeiro; Campus, 1995. 
PORTER, M. E.. What is Strategy? Harvard Business Review, november-december, 1996. A vantagem competitiva das nações. Rio de Janeiro: Campus, 1989. Estratégia competitiva. Rio de Janeiro: Elsevier, 2004.

PORTER, M. KRAMER, M. Estratégia e sociedade: o elo entre a vantagem competitiva e responsabilidade social empresarial. In: GELMAN, Jacob \& PARENTE, Juracy. Varejo socialmente responsável. Porto Alegre: Bookman, 2008.

ROBERT, M. Como empresas vencedoras dominam seus concorrentes. São Paulo: Negócio, 1998.

SENGE, P. A quinta disciplina: arte e prática da organização que aprende. 10. ed. São Paulo: Best Seller, 2002. 443 p., 2002.

SERRA, F.; TORRES, M. C.; TORRES, A.. Administração estratégica: conceitos, roteiro prático e casos. Rio de Janeiro: R\&A Editores, 2002.

STONER, J.A.F.; FREEMAN, E. Administração. Rio de Janeiro: Prentice-Hall do Brasil, 1995.

TENÓRIO, F. G. (org.). Responsabilidade social empresarial. Rio de Janeiro: FGV Editora, 2006.

VON HIPPEL. The sources of innovation. New York: Oxford University Press, 1988.

WEBER, M.. A ética protestante e o espírito do capitalismo. São Paulo: Martin Claret, 2001.

WITTMAnN, M. L. (Org.). Administração: teoria sistêmica e complexidade. 1. ed. Santa Maria: Ed. da UFSM, v. 1. 190 p., 2008. 